\title{
The Effects of Co and W on Structural Stability and Mechanical Properties of Austenitic Heat-Resistant Steel Sanicro 25: A First-Principle Study
}

\author{
Nan Dong ${ }^{1, *(\mathbb{C}, \text { Ruirui Jia }}{ }^{1}$, Jing Yang ${ }^{1}$, Jian Wang ${ }^{1}{ }^{1}$, Jie Liu ${ }^{2}$, Xudong Fang ${ }^{3}$ and Peide Han ${ }^{1, *}$ \\ 1 College of Materials Science and Engineering, Taiyuan University of Technology, Taiyuan 030024, China; \\ jrr1024@163.com (R.J.); y1774365571@126.com (J.Y.); jianwang1@126.com (J.W.) \\ 2 School of Materials Science and Engineering, Taiyuan University of Science and Technology, \\ Taiyuan 030024, China; liujie630812@126.com \\ 3 Technology Center, Taiyuan Iron and Steel (Group) Co., Ltd., Taiyuan 030003, China; fangxd@tisco.com.cn \\ * Correspondence: dongnan@tyut.edu.cn (N.D.); hanpeide@tyut.edu.cn (P.H.); Tel.: +86-182-340-89854 (N.D.); \\ +86-351-601-8843 (P.H.)
}

Received: 22 June 2020; Accepted: 31 July 2020; Published: 5 August 2020

\begin{abstract}
Sanicro 25 austenitic heat-resistant steel is expected to be used in superheaters and reheaters for ultra-supercritical power plants above $600{ }^{\circ} \mathrm{C}$ due to its excellent structural stability and high temperature mechanical properties. In this paper, the effects of $\mathrm{Co}$ and $\mathrm{W}$ on the structural stability, thermodynamic stability and mechanical properties of Sanicro 25 steel are analyzed by calculating the formation energy, binding energy, Gibbs free energy, elastic constant, Peierls stress and generalized stacking fault energy (GSFE) with first-principles calculation method. By calculating the formation energy, binding energy and Gibbs free energy, it concludes that alloying elements Co and W in Sanicro 25 steel can improve the structural stability and thermodynamic stability. It indicates that $\mathrm{W}$ and a small amount of Co can improve the plasticity and ductility of Sanicro 25 steel by calculating the bulk modulus $(B)$, shear modulus $(G)$, Young's modulus $(E)$, the $B / G$ ratio, Poisson's ratio and Peierls stress. It is found that when $\mathrm{Co}$ and $\mathrm{W}$ are far from the stacking fault region, it will promote the formation of partial dislocations and twins in the system, thereby improving its plastic deformation ability and mechanical properties.
\end{abstract}

Keywords: austenitic heat-resistant steel; first-principle study; structural stability; mechanical properties; Peierls stress; generalized stacking fault energy

\section{Introduction}

As a highly efficient and clean power generation technology, ultra-supercritical technology is the key development direction of coal-fired thermal power stations [1]. In order to improve efficiency and reduce coal consumption, the $630-650{ }^{\circ} \mathrm{C}$ ultra-supercritical unit is the next important objective of the thermal power construction. Austenitic heat-resistant steels such as $\mathrm{HR} 3 \mathrm{C}$, which are used in $600{ }^{\circ} \mathrm{C}$ ultra-supercritical units, are subjected to carbide precipitation and coarsening when operating under higher steam parameters. The structural stability is deteriorated, and the high-temperature mechanical properties and its service life will also be seriously affected [2]. New materials that can withstand high temperature loads for a long time need to be developed in order to improve efficiency of the thermal power plants [3].

Sanicro 25 steel is the main candidate material for austenitic heat-resistant steel of $630-650{ }^{\circ} \mathrm{C}$ ultra-supercritical boilers due to its high creep strength, oxidation resistance, structural stability and good processing ability [4]. By comparing the chemical composition and mechanical properties of HR3C [5] and Sanicro 25 [6] steel, it can be found that alloying elements such as Co and W play an 
important role in structural stability and high temperature mechanical properties. The creep rupture strength of Sanicro 25 steel is $45 \%$ higher than HR3C, and the corrosion resistance to high temperature steam of Sanicro 25 steel is better than HR3C [7,8]. Moreover, Zhao [9] studied the effects of W content on the microstructures and properties of Sanicro 25 steel, and concluded that the higher W content exhibits excellent thermal deformation resistance and deformation activation energy. Jang [10,11] studied the effect of $\mathrm{W}$ addition on the high temperature properties and microstructures of austenitic heat-resistant steels. W increased the volume fraction of the Laves phase and enhanced precipitation strengthening, thereby improving its mechanical properties. Furthermore, the addition of alloying elements affects deformation degree of the metal. An improved HR3C steel with 5 wt.\% Co, V and B has been developed, which has good impact toughness and fracture strength. The main reason is that the addition of Co can reduce the stacking fault energy of steels and promote the formation of twins, thus improving the mechanical properties of steels [12]. In fact, it can be found that there are indeed dislocations and twins in Sanicro 25 steel $[7,13,14]$. The stacking fault energy is an important parameter for the plastic deformation of the material. By reducing the stacking fault energy of the material, the plastic deformation ability of the material can be improved, thereby improving the strength and processing performance of the material. It has been studied to calculate the stacking fault energy of high-entropy alloys and nickel-based alloys by first principle, and it is found that Co can significantly reduce the stacking fault energy and improve its ductility and plastic deformation ability $[15,16]$. Similarly, the stacking fault energy of Co and W containing Sanicro 25 steel can be calculated by first principle calculation, and then the plastic deformation mechanism can be analyzed.

At present, the effects of alloying elements on the high temperature mechanical properties of austenitic heat-resistant steel is studied mainly from the phase of precipitation by experimental methods. However, the mechanism of Co and W impact on the structural stability and mechanical properties of Sanicro 25 steel only by experimental methods is very limited. The knowledge on how Co and W, single or common, affect the stability and mechanical properties of Sanicro 25 steel is lacking and has been in dispute; thus, more detailed analyses at the atomic-scale are still required.

In this work, we employed first-principles method to investigate the effects of Co and W addition on the structural stability and mechanical properties of Sanicro 25 austenitic heat-resistant steel. Firstly, the effects of $\mathrm{Co}$ and $\mathrm{W}$ on the structural stability of Sanicro 25 were analyzed by the formation energy, binding energy and Gibbs free energy. Secondly, the effects of alloying elements Co and W on the mechanical properties of Sanicro 25 were discussed by means of elastic modulus, Poisson's ratio, $B / G$ ratio, Peierls stress and stacking fault energy. Finally, we simply compared the calculated results with the experimental results and found that the calculated results were basically consistent with the experimental results.

\section{Computational Details}

\subsection{Models}

At temperatures around $1200{ }^{\circ} \mathrm{C}, \mathrm{Co}$ and $\mathrm{W}$ play the role of solid solution strengthening in Sanicro 25 [17]. In order to study the solid solution strengthening of Co and W in Sanicro 25 steel, we built the calculation models based on the sample after solution treatment. The research system of this paper is Sanicro 25 steel. Therefore, $\gamma$-Fe with face-centered cubic structure was chosen as the ideal crystal. The steel mainly contains $21.5-23.5$ wt.\% Cr, 23.5-26.5 wt.\% Ni, 1.0-2.0 wt.\% Co, 2.0-4.0 wt.\% $\mathrm{W}$ in addition to a number of other minor alloying constituents such as $\mathrm{Nb}, \mathrm{Cu}, \mathrm{Si}, \mathrm{B}$ and N. Based on the main chemical composition of Sanicro 25 steel, considering the number of atoms and the actual calculation efficiency, $2 \times 2 \times 2$ supercells containing 32 Fe atoms were selected as the matrix, and $16 \mathrm{Fe}$ atoms were replaced by $8 \mathrm{Cr}$ atoms and $8 \mathrm{Ni}$ atoms respectively to form the $\mathrm{Fe}_{16} \mathrm{Cr}_{8} \mathrm{Ni}_{8}$ system (approximately 22 wt.\% Cr, 25 wt.\% Ni and 53 wt.\% Fe). Subsequently, a small fraction of Fe atoms was substituted by $\mathrm{Co}(3.1 \mathrm{wt} . \%$ and $6.3 \mathrm{wt} . \%)$ and $\mathrm{W}(9.8 \mathrm{wt} . \%$ and $19.5 \mathrm{wt} . \%)$, as shown in 
Figure 1. Wherein $\mathrm{Fe}, \mathrm{Cr}, \mathrm{Ni}, \mathrm{Co}$ and $\mathrm{W}$ atoms were blue, green, pink, orange and yellow colored balls, respectively.

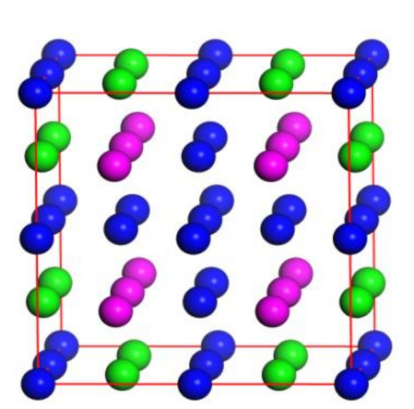

(a)

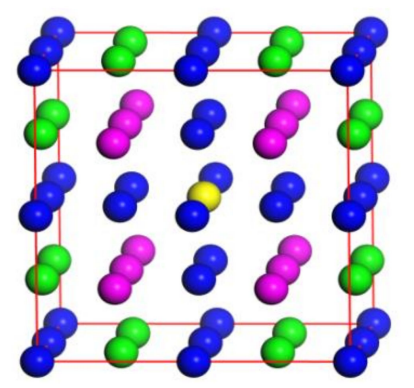

(d)

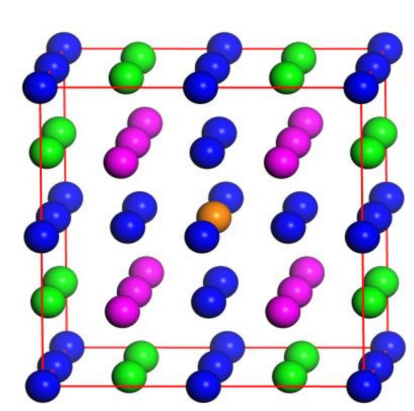

(b)

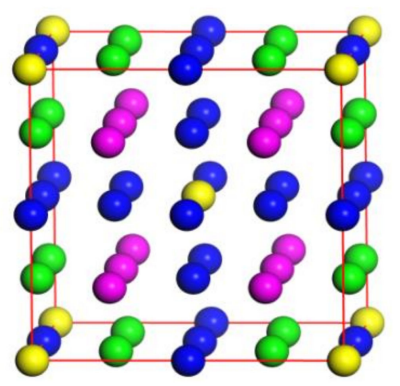

(e)

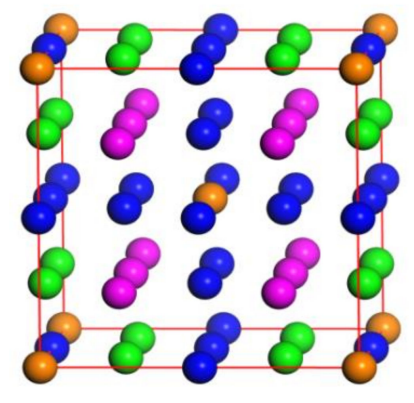

(c)
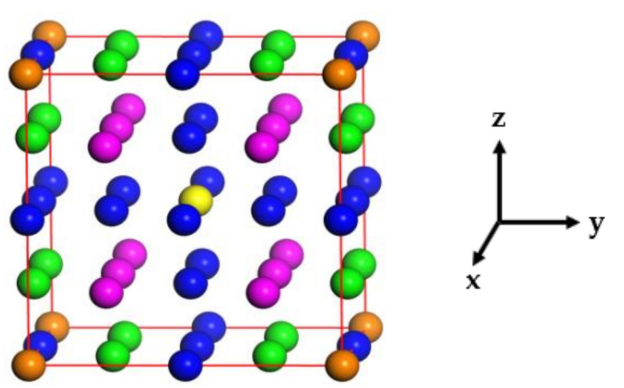

(f)

Figure 1. Schematic diagram of models for calculations: (a) $\mathrm{Fe}_{16} \mathrm{Cr}_{8} \mathrm{Ni}_{8}$; (b) $\mathrm{Fe}_{15} \mathrm{Cr}_{8} \mathrm{Ni}_{8} \mathrm{Co}$; (c) $\mathrm{Fe}_{14} \mathrm{Cr}_{8} \mathrm{Ni}_{8} \mathrm{Co}_{2}$; (d) $\mathrm{Fe}_{15} \mathrm{Cr}_{8} \mathrm{Ni}_{8} \mathrm{~W} ;$ (e) $\mathrm{Fe}_{14} \mathrm{Cr}_{8} \mathrm{Ni}_{8} \mathrm{~W}_{2}$ and (f) $\mathrm{Fe}_{14} \mathrm{Cr}_{8} \mathrm{Ni}_{8} \mathrm{CoW}$.

Fe is the close-packed face-centered cubic structure with an arrangement of ... ABCABC ... along the $<111>$ direction. In order to calculate the generalized stacking fault energy (GSFE), a 9-layer $\mathrm{Fe}_{36} \mathrm{Cr}_{18} \mathrm{Ni}_{18}$ structure was built by cleaving surface along the $<111>$ direction. The GSFE values were calculated by shearing the perfect crystal structure along the $<112>$ slip direction in two processes, as shown in Figure 2. The stacking fault model was created by fixing the bottom 5 layers of atoms and displacing the above 4 layers of atoms along $<112>$ over a distance $\mathrm{a} / \sqrt{ } 6$. A vacuum layer of $10^{-9}$ $\mathrm{m}$ was created to eliminate layer-to-layer interactions. The atomic arrangement was changed from $A B C A B C A B C$ to $A B C A B A B C A$, where indicates the position of the intrinsic stacking fault. Similarly, based on the stacking fault model, the bottom 6 layers of atoms are fixed and the above 3 layers of atoms are moved $\mathrm{a} / \sqrt{ } 6$ to obtain the two-layer twin model.

The GSFE curves by replacing $\mathrm{Co}$ and $\mathrm{W}$ on the basis of $\mathrm{Fe}_{36} \mathrm{Cr}_{18} \mathrm{Ni}_{18}$ system were calculated to study the effects of $\mathrm{Co}$ and $\mathrm{W}$ on Sanicro 25 steel stacking fault energy and plastic deformation mechanism. Two positions were substituted for $\mathrm{Co}$ and $\mathrm{W}$ atoms in the $\mathrm{Fe}_{36} \mathrm{Cr}_{18} \mathrm{Ni}_{18}$ system, one of which was far from the stacking fault region (3 layer) and the other located in stacking fault region (5 layer). The mass fraction of Co in the model is $1.4 \mathrm{wt} . \%$ and $2.8 \mathrm{wt} . \%$, then $\mathrm{W}$ is $4.3 \mathrm{wt} . \%$ and $8.6 \mathrm{wt} . \%$. 


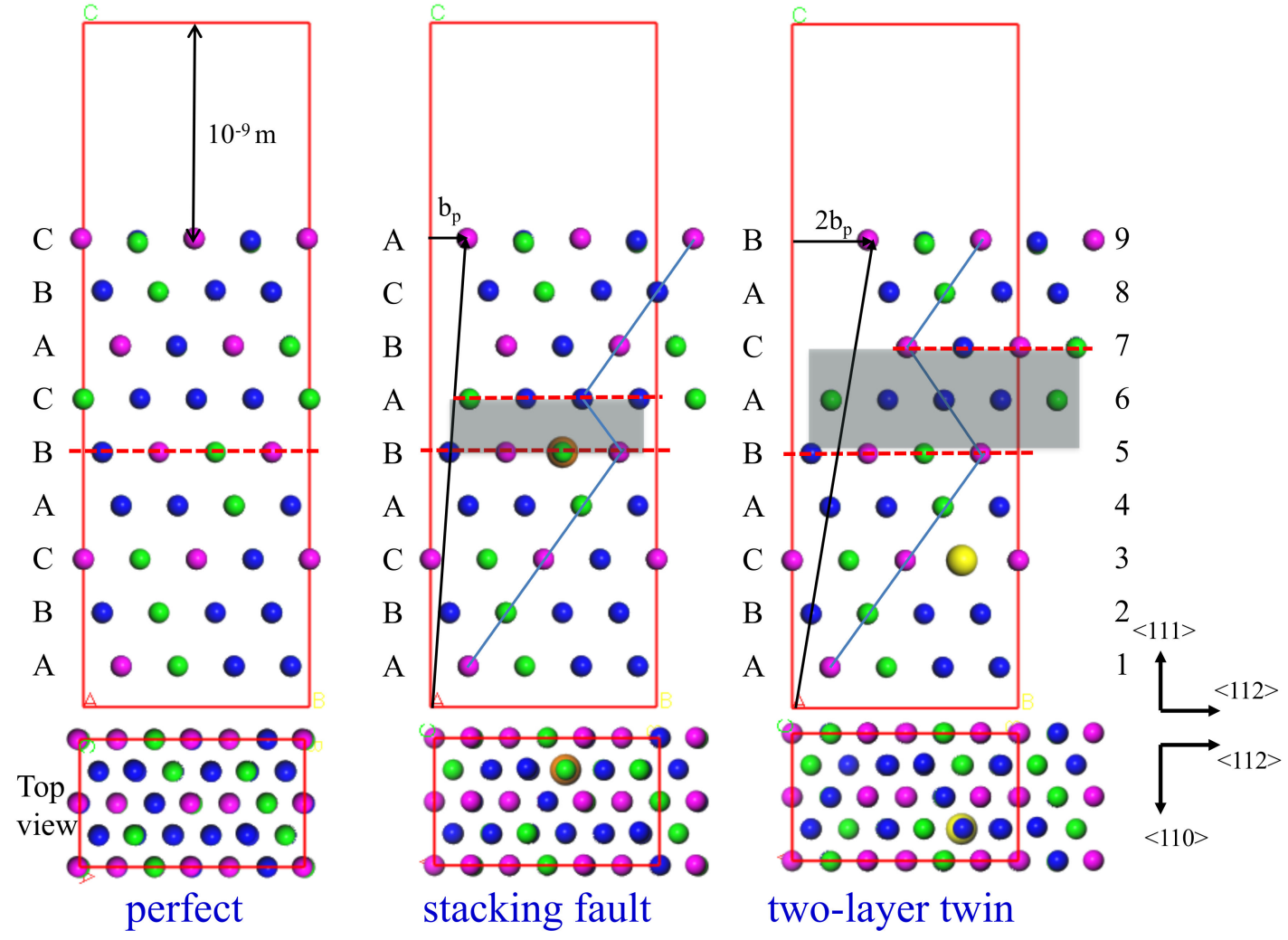

Figure 2. A schematic illustration of the formation process of twin.

\subsection{Calculation Methods}

The density functional theory calculations were carried out with the plane-wave based Cambridge Serial Total Energy Package (CASTEP) code within the generalized gradient approximation (GGA) in the parametrization by John Perdew, Kieron Burke and Matthias Ernzerhof (PBE). The plane waves have been included up to a cutoff energy of $500 \mathrm{eV}$ which yields converged results. As an austenitic stainless steel, Fe crystallizes in the fcc structure, so the magnetic effects were not considered and calculations were non-spinpolarized. The convergence parameters are as follows: total energy tolerance $10^{-5} \mathrm{eV} /$ atom, force tolerance $0.03 \mathrm{eV} / \AA$, stress component less than $0.03 \mathrm{GPa}$ and displacement less than $10^{-4} \mathrm{~nm}$. During geometry optimization, the Brillouin zone sampling was carried out with a $4 \times 4 \times 7$ Monkhorst-Pack grid of k-point [2]. Using the equilibrium structure after structural optimization, the Gibbs free energy and elastic constants of different systems are calculated in the absence of possible microstructure variations. When calculating the GSFE curves, considering the calculation model and calculation accuracy, the plane wave cutoff energy value is chosen to be $330 \mathrm{eV}$. The Brillouin zone sampling was performed using a $5 \times 3 \times 1$ Monkhorst-Pack grid of k-point [18].

\section{Results and Discussions}

\subsection{Structural Stability}

The structural constants of the above six models after structural optimization are shown in Table 1. After $\mathrm{Co}$ and $\mathrm{W}$ are dissolved in the $\mathrm{Fe}_{16} \mathrm{Cr}_{8} \mathrm{Ni}_{8}$ system, these systems are still tetragonal systems, but all of them have different degrees of volume expansion. Because the atomic radius of Co $\left(1.253 \times 10^{-12} \mathrm{~m}\right)$ and the atomic radius of $\mathrm{Fe}\left(1.241 \times 10^{-12} \mathrm{~m}\right)$ are close, the lattice distortion of the systems are relatively small and the volume of the systems containing Co change little; while the atomic radius of $\mathrm{W}\left(1.37 \times 10^{-12} \mathrm{~m}\right)$ is quite different from that of $\mathrm{Fe}$, the lattice distortion of the systems are relatively larger and the volume of the systems containing W increase obviously. With the increase of 
$\mathrm{Co}$ and $\mathrm{W}$ content, the volume expansion is more obvious. Moreover, the volume expansion of the $\mathrm{Fe}_{14} \mathrm{Cr}_{8} \mathrm{Ni}_{8} \mathrm{CoW}$ system is larger than the $\mathrm{Fe}_{15} \mathrm{Cr}_{8} \mathrm{Ni}_{8} \mathrm{Co}$ system and the $\mathrm{Fe}_{15} \mathrm{Cr}_{8} \mathrm{Ni}_{8} \mathrm{~W}$ system.

Table 1. Calculated structural constants of different systems after optimization.

\begin{tabular}{ccccc}
\hline Structure & $\alpha=\boldsymbol{\beta}=\boldsymbol{\gamma} /^{\circ}$ & $\mathbf{a}=\mathbf{b} / \mathbf{1 0}^{-\mathbf{1 0}} \mathbf{~ m}$ & $\mathbf{c} / \mathbf{1 0}^{-\mathbf{1 0}} \mathbf{~ m}$ & $\mathbf{V} / \mathbf{1 0}^{-\mathbf{3 0}} \mathbf{~ m}^{\mathbf{3}}$ \\
\hline $\mathrm{Fe}_{16} \mathrm{Cr}_{8} \mathrm{Ni}_{8}$ & 90 & 6.956 & 7.042 & 340.768 \\
$\mathrm{Fe}_{15} \mathrm{Cr}_{8} \mathrm{Ni}_{8} \mathrm{Co}$ & 90 & 6.954 & 7.059 & 341.345 \\
$\mathrm{Fe}_{14} \mathrm{Cr}_{8} \mathrm{Ni}_{8} \mathrm{Co}$ & 90 & 6.948 & 7.083 & 341.908 \\
$\mathrm{Fe}_{15} \mathrm{Cr}_{8} \mathrm{Ni}_{8} \mathrm{~W}$ & 90 & 7.010 & 7.058 & 346.817 \\
$\mathrm{Fe}_{14} \mathrm{Cr}_{8} \mathrm{Ni}_{8} \mathrm{~W}_{2}$ & 90 & 7.079 & 7.063 & 353.940 \\
$\mathrm{Fe}_{14} \mathrm{Cr}_{8} \mathrm{Ni}_{8} \mathrm{CoW}$ & 90 & 7.003 & 7.082 & 347.330 \\
\hline
\end{tabular}

The degree of difficulty of dissolving $\mathrm{Co}$ and $\mathrm{W}$ in the $\mathrm{Fe}_{16} \mathrm{Cr}_{8} \mathrm{Ni}_{8}$ system to form new systems can be measured by the formation energy, which is the energy difference before and after the formation of the system [19]. The calculation formula is as follows:

$$
E_{f}=\frac{1}{\Sigma N_{i}}\left[E_{\text {total }}-\Sigma\left(N_{i} E_{\text {atom }}^{i}\right)\right]
$$

where $E_{\text {total }}$ is the total energy of each system after structural optimization, $N_{i}$ is the number of $i$ atoms $(i=\mathrm{Fe}, \mathrm{Cr}, \mathrm{Ni}, \mathrm{Co}$ or $\mathrm{W})$ in the system and $E_{\text {atom }}^{i}$ is the monatomic energy of atom $i$ in its elemental state. The same calculation conditions as the structural optimization are used to calculate the monatomic energy. When the formation energy is negative, it indicates that the system is easy to form. On the contrary, the system is difficult to form when the formation energy is positive [19]. The formation energy of each system can be shown in Figure 3a. It can be seen that the formation energy values of all systems are between 0.125 and $0.20 \mathrm{eV} /$ atom, indicating that all systems are relatively easy to form. When $\mathrm{Co}$ is dissolved into the $\mathrm{Fe}_{16} \mathrm{Cr}_{8} \mathrm{Ni}_{8}$ system, its formation energy decreases, indicating that the system is relatively easy to form. Then the formation energy decreases with the increase of Co content, and the system is more easily formed. Conversely, when $\mathrm{W}$ is dissolved into the $\mathrm{Fe}_{16} \mathrm{Cr}_{8} \mathrm{Ni}_{8}$ system, the increase of formation energy indicates that the system is not easy to form. Furthermore, with the increase of $\mathrm{W}$ content, the formation energy increases, indicating that the system is relatively difficult to form. Furthermore, the value of the formation energy also indicates that the $\mathrm{Fe}_{14} \mathrm{Cr}_{8} \mathrm{Ni}_{8} \mathrm{CoW}$ system is more difficult to form than the $\mathrm{Fe}_{15} \mathrm{Cr}_{8} \mathrm{Ni}_{8} \mathrm{Co}$ system, but it is easier to form than the $\mathrm{Fe}_{15} \mathrm{Cr}_{8} \mathrm{Ni}_{8} \mathrm{~W}$ system.
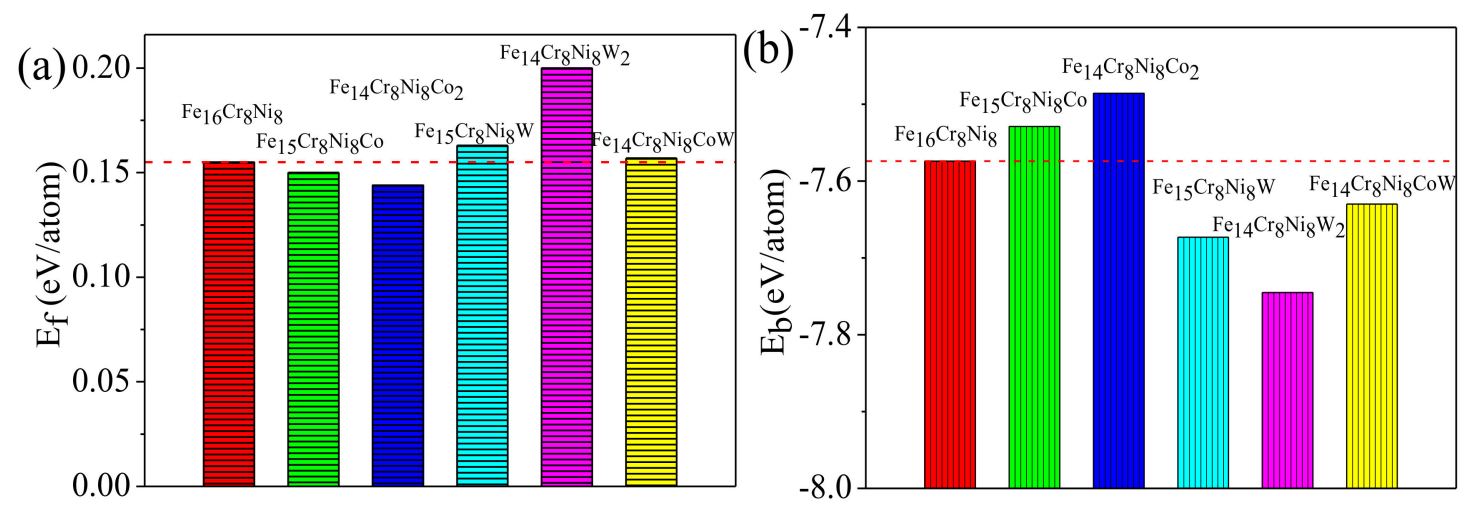

Figure 3. Forming energy $E_{f}$ and binding energy $E_{b}$ of different systems: (a) $E_{f}$ and (b) $E_{b}$.

In order to analyze the structural stability of $\mathrm{Co}$ and $\mathrm{W}$ dissolved in the $\mathrm{Fe}_{16} \mathrm{Cr}_{8} \mathrm{Ni}_{8}$ system, it is necessary to calculate the binding energy. The binding energy refers to the energy that is released upon 
the creation of a bound state. Therefore, the greater the absolute value of the binding energy, the better the structural stability $[2,20]$. The calculation formula of binding energy is as follows:

$$
E_{b}=\frac{1}{\Sigma N_{i}}\left[E_{\text {total }}-\Sigma\left(N_{i} E_{\text {iso }}^{i}\right)\right]
$$

where $E_{\text {iso }}^{i}$ is the energy of $i$ atom ( $i=\mathrm{Fe}, \mathrm{Cr}, \mathrm{Ni}, \mathrm{Co}$ or $\mathrm{W}$ ) in isolated state, which is the energy calculated by fully relaxing the $i$ atom at the center of a simple cubic structure with a lattice constant of $10^{-9} \mathrm{~m}$. The binding energy of each system is shown in Figure 3b. It can be seen that the binding energy values of all systems are negative, indicating that all systems have good structural stability. When $\mathrm{Co}$ is dissolved in the $\mathrm{Fe}_{16} \mathrm{Cr}_{8} \mathrm{Ni}_{8}$ system, the structural stability of the system decreases with the increase of Co content. In contrast, when $\mathrm{W}$ is dissolved in the $\mathrm{Fe}_{16} \mathrm{Cr}_{8} \mathrm{Ni}_{8}$ system, the increase of the absolute value of the binding energy means that the system has good structural stability. Furthermore, increasing $\mathrm{W}$ content can improve the structural stability of the system. Moreover, the structural stability of the $\mathrm{Fe}_{14} \mathrm{Cr}_{8} \mathrm{Ni}_{8} \mathrm{CoW}$ system is lower than that of the $\mathrm{Fe}_{15} \mathrm{Cr}_{8} \mathrm{Ni}_{8} \mathrm{~W}$ system, but its structural stability is higher than that of the $\mathrm{Fe}_{15} \mathrm{Cr}_{8} \mathrm{Ni}_{8}$ Co system.

In order to explore the mechanism of $\mathrm{Co}$ and $\mathrm{W}$ in Sanicro 25 steel from the perspective of microscopic electrons, charge density distribution maps were drawn to analyze the electronic properties of different systems. As shown in Figure 4, the electrons are concentrated around the atoms in a spherical distribution and the electron distribution between atoms is uniform, which indicates that there are metal bonds in systems. When $\mathrm{Co}$ and $\mathrm{W}$ are dissolved in the $\mathrm{Fe}_{16} \mathrm{Cr}_{8} \mathrm{Ni}_{8}$ system, the charge distribution around atoms change little, which shows that all systems are stable. However, through careful comparison, it can be found that when $\mathrm{Co}$ is dissolved in the $\mathrm{Fe}_{16} \mathrm{Cr}_{8} \mathrm{Ni}_{8}$ system, the surrounding charge distribution is slightly reduced, and the bonds between $\mathrm{Co}$ and surrounding atoms are slightly worse, so the structural stability of the system is also reduced. Conversely, when $\mathrm{W}$ is dissolved in the $\mathrm{Fe}_{16} \mathrm{Cr}_{8} \mathrm{Ni}_{8}$ system, the surrounding charge distribution increases, and the bonds between $\mathrm{W}$ and surrounding atoms are closer, so $\mathrm{W}$ will enhance the structural stability of the system. In addition, compared to the $\mathrm{Fe}_{16} \mathrm{Cr}_{8} \mathrm{Ni}_{8}$ system, the charge distribution around the $\mathrm{Fe}_{14} \mathrm{Cr}_{8} \mathrm{Ni}_{8} \mathrm{CoW}$ system is increased, so the structural stability of the $\mathrm{Fe}_{14} \mathrm{Cr}_{8} \mathrm{Ni}_{8} \mathrm{CoW}$ system is also improved. The results of charge density analysis are consistent with those of binding energy calculation.

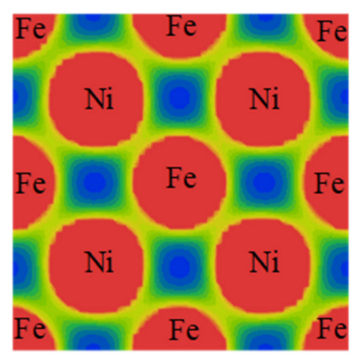

(a)

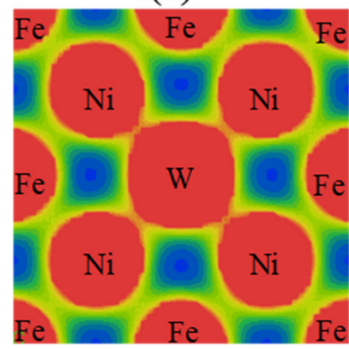

(d)

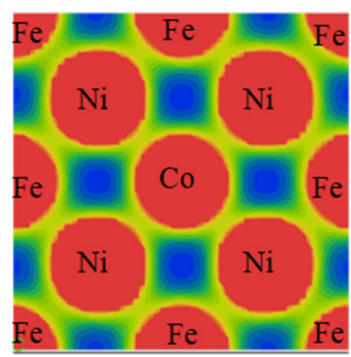

(b)

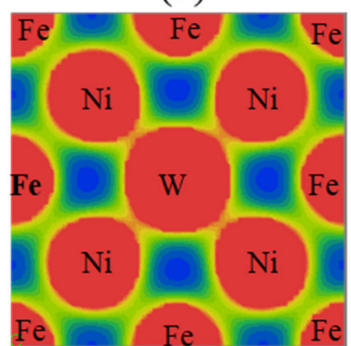

(e)

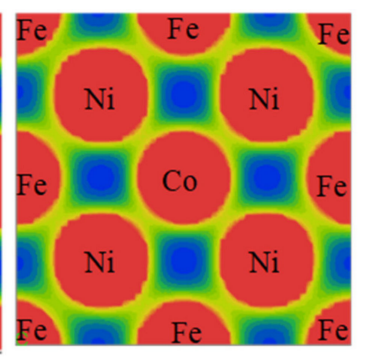

(c)

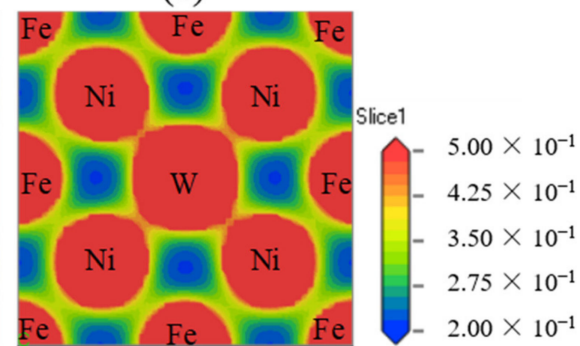

(f)

Figure 4. Charge density distribution maps of different systems in (010) plane: (a) Fe16Cr8Ni8; (b) Fe15Cr8Ni8Co; (c) Fe14Cr8Ni8Co2; (d) Fe15Cr8Ni8W; (e) Fe14Cr8Ni8W2 and (f) Fe14Cr8Ni8CoW. 
The Gibbs free energy curve is often used to analyze the structural stability of materials at different temperatures [21]. The smaller the Gibbs free energy value is, the higher the thermodynamic stability is $[22,23]$. In order to study the structural stability of $\mathrm{Co}$ and $\mathrm{W}$ dissolved in the $\mathrm{Fe}_{16} \mathrm{Cr}_{8} \mathrm{Ni}_{8}$ system at $630-650{ }^{\circ} \mathrm{C}$, the curve of Gibbs free energy with temperature is plotted, as shown in Figure 5. At -273 to $727^{\circ} \mathrm{C}$, the Gibbs free energy decreased with increasing temperature in all systems, that is, all systems become stable with the increase of temperature. Especially at $630-650{ }^{\circ} \mathrm{C}$, all systems have good thermodynamic stability. When $\mathrm{Co}$ and $\mathrm{W}$ are dissolved into the $\mathrm{Fe}_{16} \mathrm{Cr}_{8} \mathrm{Ni}_{8}$ system, the Gibbs free energy decreases more sharply and the thermodynamic stability is stronger. Moreover, it can also be found that $\mathrm{W}$ can stabilize the $\mathrm{Fe}_{16} \mathrm{Cr}_{8} \mathrm{Ni}_{8}$ system more than $\mathrm{Co}$. Figures $3 \mathrm{~b}, 4$ and 5 consistently illustrate that $\mathrm{Co}$ and $\mathrm{W}$ can be stably present in the Fe-Cr-Ni system.

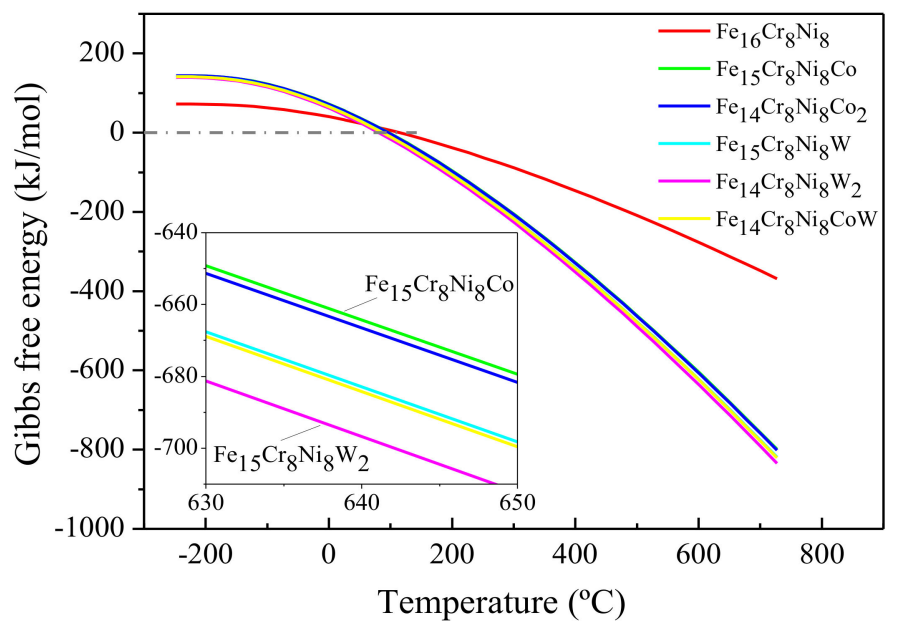

Figure 5. The relationships between Gibbs free energy and temperature in different systems.

\subsection{Elastic Constants Calculation}

In addition to structural stability and thermodynamic stability, mechanical stability is also an important criterion to estimate whether the crystal structure is stable or not. The elastic constants reflect the ability of the crystal material to cope with external strain and are closely related to the mechanical properties of the material [24]. Using the equilibrium structure after structural optimization, the elastic constants and modulus of different systems are calculated through the stress-strain method based on a generalized Hooke's Law [25]: $\sigma_{\mathrm{i}}=\mathrm{C}_{\mathrm{ij}} \varepsilon_{\mathrm{j}}$, where $\sigma_{\mathrm{i}}$ is the tensile stress and $\varepsilon_{\mathrm{j}}$ is the longitudinal strain. In our calculations, the elastic constants $C_{i j}$ can be directly obtained from the results after calculating the "Elastic Constants" in CASTEP code. The criteria of mechanical stability can be evaluated by single-crystal elastic constants according to the Born-Huang criterion, which is dependent on the crystal system [26]. The systems studied in this paper are tetragonal crystal systems with six independent elastic constants $\left(\mathrm{C}_{11}, \mathrm{C}_{12}, \mathrm{C}_{13}, \mathrm{C}_{33}, \mathrm{C}_{44}\right.$ and $\left.\mathrm{C}_{66}\right)$ and the elastic constants calculated by the six models are shown in Table 2. The condition for the stable mechanical properties of the tetragonal system is $\mathrm{C}_{11}$ $>0, \mathrm{C}_{33}>0, \mathrm{C}_{44}>0, \mathrm{C}_{66}>0, \mathrm{C}_{11}-\mathrm{C}_{12}>0, \mathrm{C}_{11}+\mathrm{C}_{33}-2 \mathrm{C}_{12}>0$ and $2\left(\mathrm{C}_{11}+\mathrm{C}_{12}\right)+\mathrm{C}_{33}+4 \mathrm{C}_{13}>0$ [24]. It can be found by calculation that all systems satisfy the mechanical stability criterion of tetragonal system, and the mechanical properties of these systems are stable.

Table 2. Calculated single-crystal elastic constants for different systems.

\begin{tabular}{ccccccc}
\hline Elastic Constants & $\mathrm{C}_{\mathbf{1 1}} / \mathrm{GPa}$ & $\mathrm{C}_{\mathbf{1 2}} / \mathrm{GPa}$ & $\mathrm{C}_{\mathbf{1 3}} / \mathrm{GPa}$ & $\mathrm{C}_{\mathbf{3 3}} / \mathrm{GPa}$ & $\mathrm{C}_{\mathbf{4 4}} / \mathrm{GPa}$ & $\mathrm{C}_{\mathbf{6 6}} / \mathrm{GPa}$ \\
\hline $\mathrm{Fe}_{16} \mathrm{Cr}_{8} \mathrm{Ni}_{8}$ & 379.505 & 222.616 & 190.723 & 429.976 & 199.253 & 207.725 \\
$\mathrm{Fe}_{15} \mathrm{Cr}_{8} \mathrm{Ni}_{8} \mathrm{Co}$ & 399.361 & 219.855 & 201.078 & 431.200 & 193.911 & 208.585 \\
$\mathrm{Fe}_{14} \mathrm{Cr}_{8} \mathrm{Ni}_{8} \mathrm{Co}_{2}$ & 392.879 & 216.273 & 192.282 & 407.783 & 193.120 & 206.080 \\
$\mathrm{Fe}_{15} \mathrm{Cr}_{8} \mathrm{Ni}_{8} \mathrm{~W}$ & 400.161 & 217.589 & 208.935 & 406.525 & 190.279 & 206.765 \\
$\mathrm{Fe}_{14} \mathrm{Cr}_{8} \mathrm{Ni}_{8} \mathrm{~W}_{2}$ & 410.875 & 242.675 & 246.390 & 366.543 & 182.459 & 193.174 \\
$\mathrm{Fe}_{14} \mathrm{Cr}_{8} \mathrm{Ni}_{8} \mathrm{CoW}$ & 399.863 & 226.603 & 214.530 & 383.379 & 187.364 & 204.087 \\
\hline
\end{tabular}


Many elastic properties of crystals can also be obtained by calculating elastic constants, such as bulk modulus $B$, shear modulus $G$, Young's modulus $E$ and Poisson's ratio $v$, et cetera. The elastic modulus of the polycrystalline system can be obtained using the Voight-Reuss-Hill average scheme, the calculation formulas of $B, G, E$ and $v$ are as follows $[27,28]$ :

$$
\begin{gathered}
B=\frac{1}{9}\left(C_{11}+C_{22}+C_{33}\right)+\frac{2}{9}\left(C_{12}+C_{13}+C_{23}\right) \\
G=\frac{1}{15}\left(C_{11}+C_{22}+C_{33}-C_{12}-C_{13}-C_{23}\right)+\frac{1}{5}\left(C_{44}+C_{55}+C_{66}\right) \\
E=\frac{9 G B}{G+3 B} \\
v=\frac{3 B-2 G}{2(G+3 B)}
\end{gathered}
$$

The bulk modulus $B$, shear modulus $G$ and Young's modulus $E$ of the different systems obtained by calculation are shown in Figure 6. The bulk modulus characterizes the ability of the material to resist deformation under the applied stress, and the greater the value of the bulk modulus, the stronger the resistance to deformation. In general, the large value of bulk modulus indicates that the material has high compressive strength [29]. Shear modulus is the ratio of shear stress to shear strain that characterizes the material's ability to resist shear strain. The larger the values of the shear modulus, the stronger the shear strain resistance. Young's modulus is an important parameter to characterize the stiffness of a material. The smaller the value of the Young's modulus, the lower the stiffness of the material.
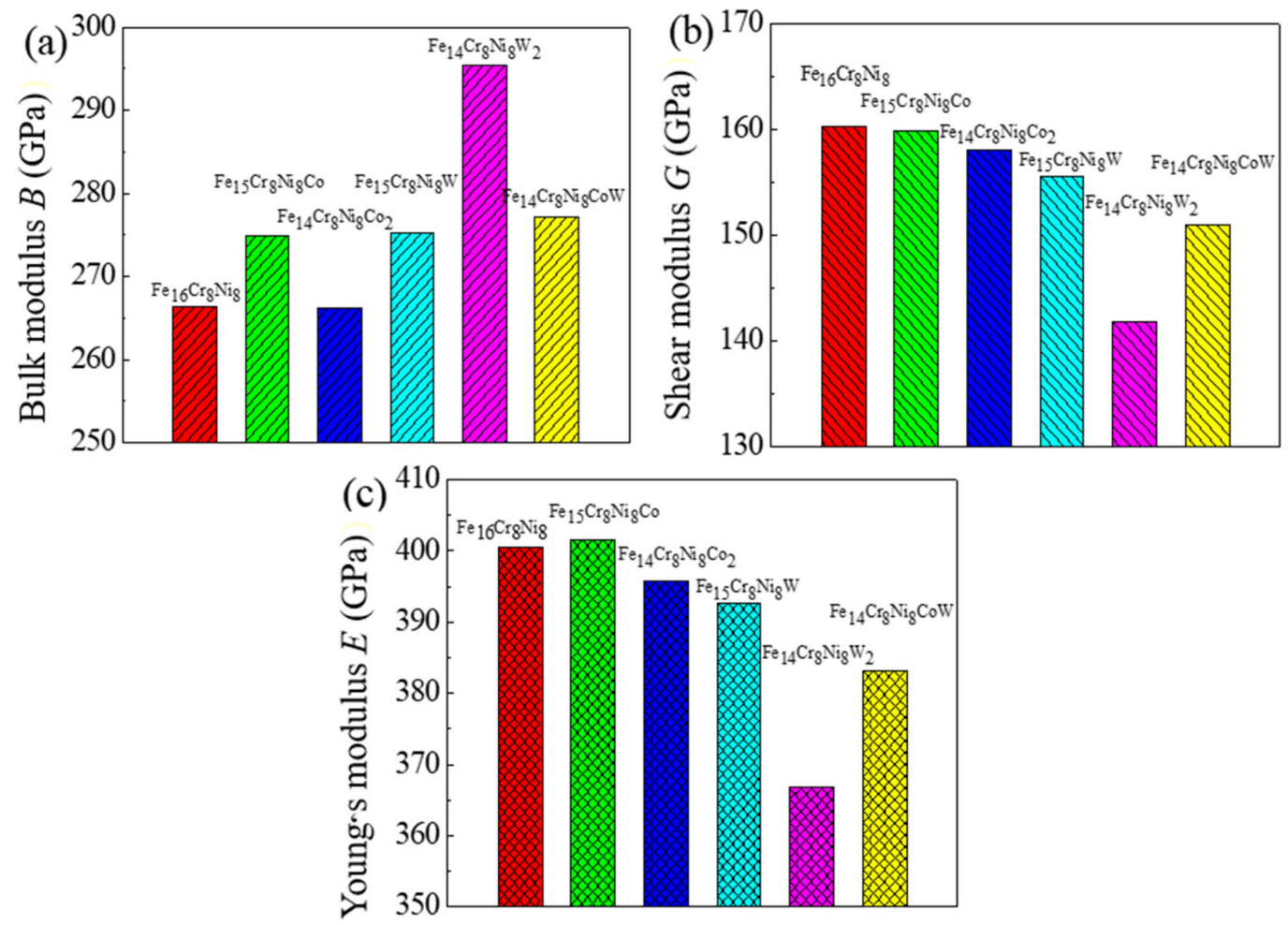

Figure 6. Calculated elastic modulus of different systems: (a) the bulk modulus $B$, (b) shear modulus $G$ and (c) Young's modulus $E$.

It can be seen from Figure $6 \mathrm{a}$ that as the Co content increases, the bulk modulus first increases and then decreases, and the compressive strength also first increases and then decreases. With the increase of $\mathrm{W}$ content dissolved in the $\mathrm{Fe}_{16} \mathrm{Cr}_{8} \mathrm{Ni}_{8}$ system, it can be seen that bulk modulus gradually increases, 
indicating that its resistance to volume deformation is improved and the compressive strength is increased. It can be seen from Figure $6 \mathrm{~b}$ that the shear modulus decreases with the increase of $\mathrm{Co}$ and $\mathrm{W}$ content, indicating that the resistance to shear strain is decreased. In Figure $6 \mathrm{c}$, as the Co content increases, the stiffness of the system increases first and then decreases. Besides, the stiffness decreases as the $\mathrm{W}$ content increases. Finally, compared to the $\mathrm{Fe}_{16} \mathrm{Cr}_{8} \mathrm{Ni}_{8}$ system, the $\mathrm{Fe}_{14} \mathrm{Cr}_{8} \mathrm{Ni}_{8} \mathrm{CoW}$ system has higher compressive strength and lower shear deformation resistance and stiffness.

Poisson's ratio is often used to estimate the stability of the material's crystal shear resistance. The greater the value, the better the plasticity of the material [23]. The ratio of bulk modulus to shear modulus, $B / G$, is often used to distinguish a material is brittle or ductile. When $B / G \geq 1.75$, the ductility of the material is great and the larger the $B / G$, the better the ductility [30-32]. It can be seen from Figure 7 that when $\mathrm{Co}$ is dissolved in the $\mathrm{Fe}_{16} \mathrm{Cr}_{8} \mathrm{Ni}_{8}$ system, as the Co content increases, the Poisson's ratio and $B / G$ value of the system first increases and then decreases, indicating that its plasticity and ductility also first increase and then decrease. It can also be found that when $\mathrm{W}$ is dissolved in the $\mathrm{Fe}_{16} \mathrm{Cr}_{8} \mathrm{Ni}_{8}$ system, the increases of Poisson's ratio and $B / G$ means that the system have great plasticity and ductility. Furthermore, with the increase of $W$ content, the Poisson's ratio and $B / G$ value increases, indicating that the plasticity and ductility of the system is better. In addition, the $\mathrm{Fe}_{14} \mathrm{Cr}_{8} \mathrm{Ni}_{8} \mathrm{CoW}$ system has higher plasticity and ductility compared to the $\mathrm{Fe}_{15} \mathrm{Cr}_{8} \mathrm{Ni}_{8} \mathrm{Co}$ and the $\mathrm{Fe}_{15} \mathrm{Cr}_{8} \mathrm{Ni}_{8} \mathrm{~W}$ systems. This shows that $\mathrm{Co}$ and $\mathrm{W}$ jointly improve the plasticity and ductility.
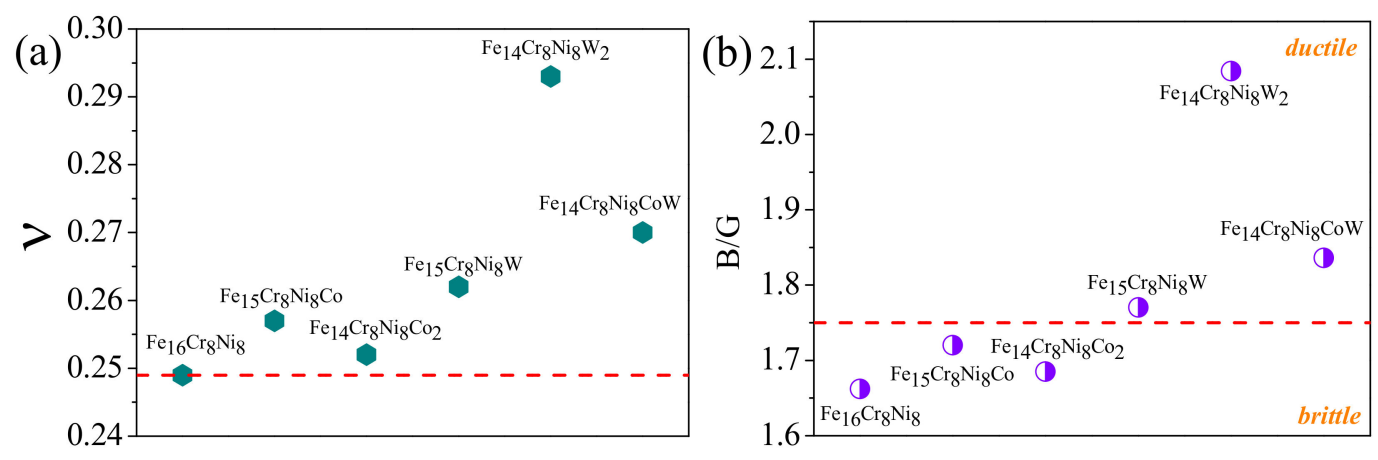

Figure 7. Calculated Poisson's ratio and B/G values of different systems: (a) Poisson's ratio and (b) B/G.

In order to study the effect of single crystal elastic anisotropy on its mechanical properties, we use the Zener's anisotropy parameter $A_{Z}$ to calculate the elastic anisotropy of different systems, the formula of $A_{Z}$ is as follows [33]:

$$
A_{Z}=\frac{2 C_{44}}{C_{11}-C_{12}}
$$

The calculated Zener's anisotropy parameters of different systems are shown in Figure 8. Generally, the $A_{Z}$ of isotropic materials is equal to 1 . Therefore, the greater the degree of $A_{Z}$ deviation, the greater the degree of elastic anisotropy in the system. When $\mathrm{Co}$ and $\mathrm{W}$ are dissolved in the $\mathrm{Fe}_{16} \mathrm{Cr}_{8} \mathrm{Ni}_{8}$ system, the degree of elastic anisotropy decreases.

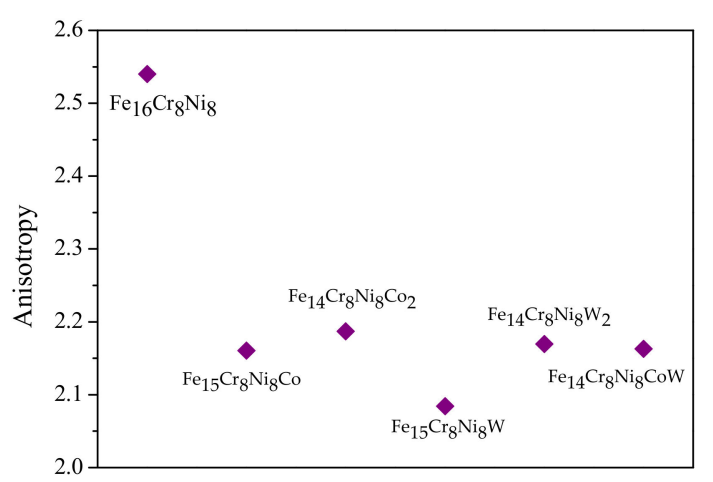

Figure 8. Calculated the Zener's anisotropy parameter of different systems. 


\subsection{Peierls Stress Calculation}

The Peierls stress can also estimate the plastic deformation ability of these systems. During the process of dislocation movement (before reaching the equilibrium position), the dislocation center will deviate from the equilibrium position to increase the crystal energy to form an energy barrier, which is the dislocation motion resistance caused by the crystal lattice, also called Peierls stress. The smaller the values of the Peierls stress, the easier the dislocations are to slip. Its formula is as follows [34]:

$$
\tau_{P-N} \approx \frac{2 G}{1-v} e^{-\left[\frac{2 \pi p}{(1-v) q}\right]} \approx \frac{2 G}{1-v} e^{-\left(\frac{2 \pi W}{q}\right)}
$$

where $p$ is the surface spacing of the slip surface, $q$ is the atomic spacing in the slip direction, $W=p /(1-v)$ is the width of the dislocation. This paper selects the (111) and (001) crystal planes to calculate the Peierls stress of different systems, as shown in Figure 9. The slip directions of (111) and (001) crystal planes are both the easiest slip direction (110). It can be found that the calculation results of Peierls stress in different crystal planes are consistent with the code that the face-centered cubic structure preferentially slides along its (111) close-packed surface. It can be seen from Figure 8 that Co has little effect on the Peierls stress of the (111) and (001) crystal plane. On the contrary, alloying elements W dissolved in the $\mathrm{Fe}_{16} \mathrm{Cr}_{8} \mathrm{Ni}_{8}$ system reduces Peierls stress, thereby promoting the dislocations slip. Furthermore, with the increase of $\mathrm{W}$ content, the Peierls stress decreases, indicating that the dislocations motion resistance of the system is reduced. Compared with the $\mathrm{Fe}_{15} \mathrm{Cr}_{8} \mathrm{Ni}_{8} \mathrm{Co}$ and $\mathrm{Fe}_{15} \mathrm{Cr}_{8} \mathrm{Ni}_{8} \mathrm{~W}$ systems, the $\mathrm{Fe}_{14} \mathrm{Cr}_{8} \mathrm{Ni}_{8} \mathrm{CoW}$ system has smaller dislocations motion resistance on the (111) and (001) crystal plane. This indicates that the interaction of $\mathrm{Co}$ and $\mathrm{W}$ can significantly reduce the dislocations motion resistance of the $\mathrm{Fe}_{14} \mathrm{Cr}_{8} \mathrm{Ni}_{8} \mathrm{CoW}$ system.
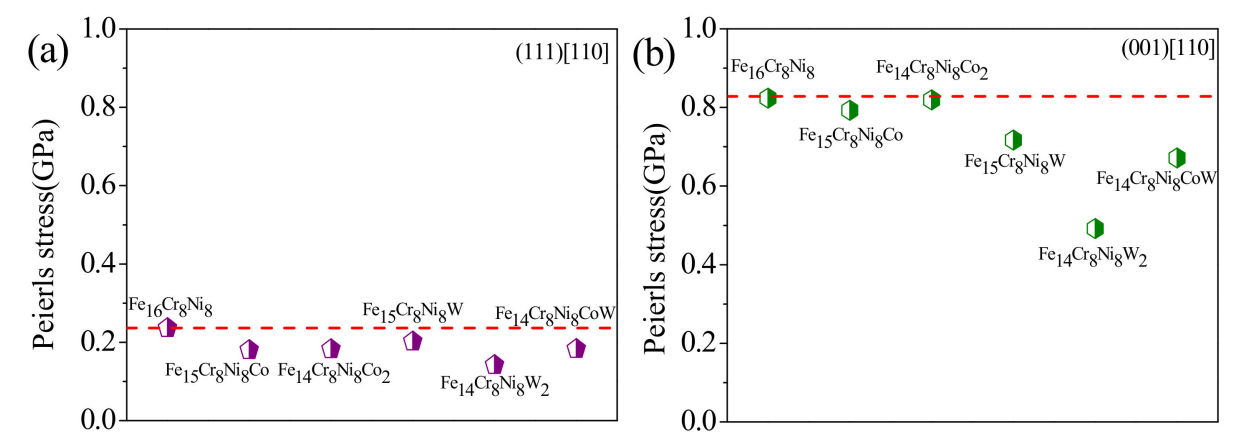

Figure 9. Calculated Peierls stresses of different systems: (a) (111) crystal plane and (b) (001) crystal plane.

\subsection{Stacking Fault Energy Calculation}

To further explain the effects of $\mathrm{Co}$ and $\mathrm{W}$ on plastic deformation in Sanicro 25 steel from the perspective of dislocations and twins, we analyzed the GSFE. In this paper, the GSFE value is calculated by [35]:

$$
\gamma=\frac{E_{u}-E_{0}}{S}
$$

where $E_{u}$ is the total energy of the supercell with the fault vector (varies from 0.0 to 2.0 with a step of 0.1 ), $E_{0}$ is the total energy of the perfect fcc supercell and $S$ is the area of the stacking fault region. Although the calculation is assumed to be at $0 \mathrm{~K}$, the results of GSFE would reflect the effect tendency of W and Co at high temperature [36,37]. Figure 10 shows the first-principles calculated GSFE curves of different systems. The GSFE curve of the $\mathrm{Fe}_{36} \mathrm{Cr}_{18} \mathrm{Ni}_{18}$ system is similar to the $\mathrm{Fe}_{13} \mathrm{Cr}_{5} \mathrm{Ni}_{6}$ in reference [38]. It can be seen that Co will reduce unstable SFE $\left(\gamma_{u s f}\right)$ and when Co is far from the stacking fault region, the intrinsic SFE $\left(\gamma_{i s f}\right)$ will decrease, which promotes the system to slip in $<112>$ direction. Furthermore, the $\mathrm{Fe}_{35} \mathrm{Cr}_{18} \mathrm{Ni}_{18} \mathrm{~W}$ and the $\mathrm{Fe}_{34} \mathrm{Cr}_{18} \mathrm{Ni}_{18} \mathrm{~W}_{2}$ curves are mostly above the $\mathrm{Fe}_{36} \mathrm{Cr}_{18} \mathrm{Ni}_{18}$ curve. When Co and $\mathrm{W}$ locate in the stacking fault region, the $\mathrm{Fe}_{34} \mathrm{Cr}_{18} \mathrm{Ni}_{18} \mathrm{CoW}$ curve is above the $\mathrm{Fe}_{36} \mathrm{Cr}_{18} \mathrm{Ni}_{18}$ curve. 

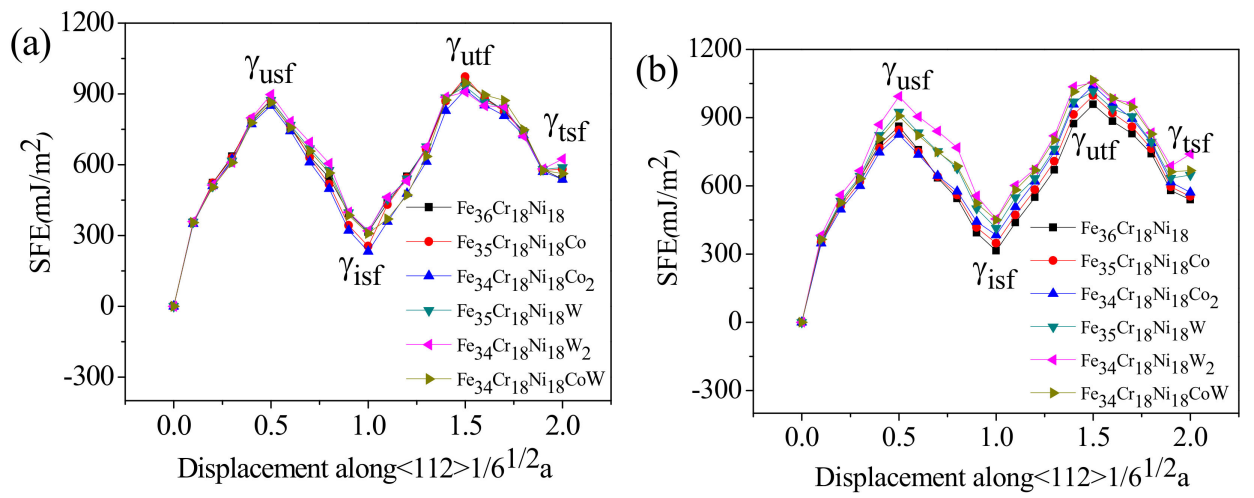

Figure 10. The GSFE curves of different systems: (a) The alloying element is far from the stacking fault region. (b) The alloying element locates in stacking fault region.

Related studies showed that the GSFE values, including intrinsic SFE $\left(\gamma_{i s f}\right)$, unstable SFE $\left(\gamma_{u s f}\right)$, twin SFE $\left(\gamma_{t s f}\right)$ and unstable twin SFE $\left(\gamma_{u t f}\right)$ all affect the plastic deformation mechanism. The large value of $\gamma_{\text {usf } f} \gamma_{\text {isf }}$ indicates that the system is easy to form partial dislocations from full dislocations [39]. It can be found from Figure 11a that the $\gamma_{u s f} / \gamma_{\text {isf }}$ values increase when Co and W are far from the stacking fault region. It indicates that $\mathrm{Co}$ and $\mathrm{W}$ are prone to generate partial dislocations when they are far from the stacking fault region and the higher the content of $\mathrm{Co}$ and $\mathrm{W}$, the easier it is to generate partial dislocations. When Co and $\mathrm{W}$ locates in the stacking fault region, the decrease of $\gamma_{u s f} \gamma_{\text {isf }}$ value shows that all different systems tend to generate full dislocations.

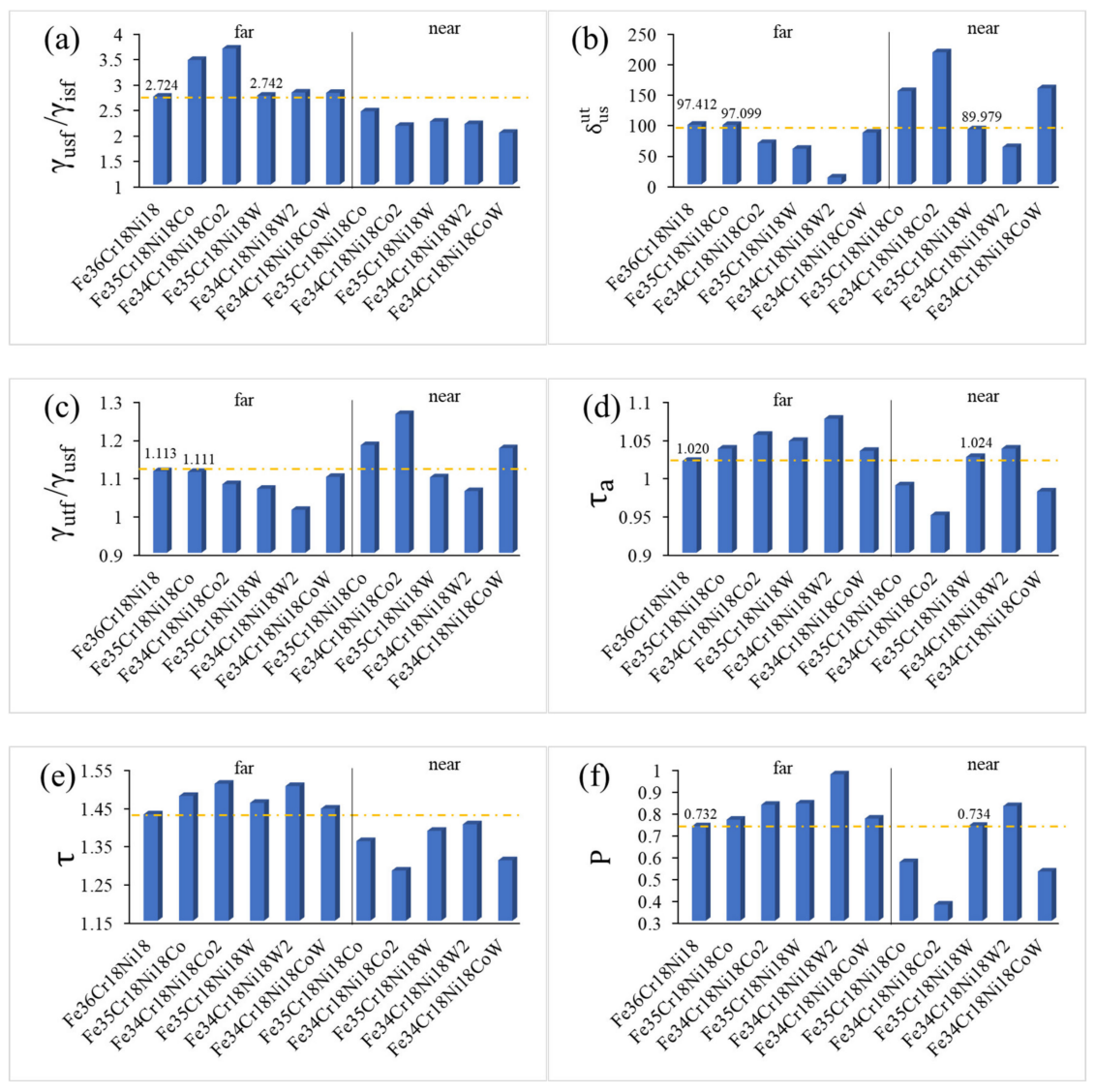

Figure 11. Ranking of different systems in the present work based on; (a) ratio of $\gamma_{u s f} / \gamma_{i s f},(\mathbf{b}) \delta_{\text {us }}^{u t}$ (c) ratio of $\gamma_{u t f} / \gamma_{u s f}$, (d) twinnability $\tau_{a}$ for crack tip twinning, (e) twinnability $\tau$ for grain boundary twinning and (f) twinnability $P$ for inherent twinning. 
Slip and twinning are two ways of plastic deformation. The way in which metal is plastically deformed is determined by $\delta_{\text {us }}^{u t}\left(\delta_{\text {us }}^{u t} \equiv \gamma_{u t f}-\gamma_{u s f}\right)$ [40]. If $\delta_{\text {us }}^{u t}>0$, it indicates that during the plastic deformation process, after the formation of the stacking fault, it is more inclined to produce deformation by slipping; if $\delta_{\text {us }}^{u t}<0$, after the formation of stacking faults, it is more likely to produce deformation by twinning. It can be seen from Figure $11 \mathrm{~b}$ that the values of $\delta_{\text {us }}^{u t}$ decrease when Co is far from the stacking fault region, which increases the possibility that the Fe-Cr-Ni system is deformed by twinning. When Co locates in the stacking fault region, the increase of $\delta_{\mathrm{us}}^{u t}$ indicates that Co can promote the ability of the Fe-Cr-Ni system to deform in a slipping manner. A decrease in the values of $\delta_{\mathrm{us}}^{u t}$ when $\mathrm{W}$ is dissolved in the $\mathrm{Fe}_{36} \mathrm{Cr}_{18} \mathrm{Ni}_{18}$ system indicates that $\mathrm{W}$ promotes deformation by twinning. Additionally, the higher the Co and $\mathrm{W}$ content, the higher the tendency to produce deformation by twinning. When $\mathrm{Co}$ and $\mathrm{W}$ are far from the stacking fault region, the $\delta_{\text {us }}^{u t}$ of the $\mathrm{Fe}_{34} \mathrm{Cr}_{18} \mathrm{Ni}_{18} \mathrm{CoW}$ system is lower than the $\mathrm{Fe}_{36} \mathrm{Cr}_{18} \mathrm{Ni}_{18}$ system, indicating that the interaction of $\mathrm{Co}$ and $\mathrm{W}$ promotes deformation by twinning. When Co and $\mathrm{W}$ locates in the stacking fault region, the values of $\delta_{\mathrm{us}}^{u t}$ increase indicating that the $\mathrm{Fe}_{34} \mathrm{Cr}_{18} \mathrm{Ni}_{18} \mathrm{CoW}$ system is more easily deformed by slipping.

In addition, there are many criteria to estimate the tendency of twinning. Tadmor and Hai [41] found that $\gamma_{u t f} / \gamma_{u s f}$ can reflect the twinning tendency. When this value is smaller, the twinning is more likely to appear in the system. Tadmor and Bernstein $[42,43]$ used a statistical average of the twinning tendency under all orientation conditions in a polycrystalline system to define the twinning ability of a homogeneous polycrystalline material, called crack tip twinning criterion:

$$
\tau_{a}=\left[1.136-0.151 \frac{\gamma_{i s f}}{\gamma_{u s f}}\right] \sqrt{\frac{\gamma_{u s f}}{\gamma_{u t f}}}
$$

$\tau_{a}$ is the tendency of the material to undergo deformation twinning. When $\tau_{a}<1$, the deformation is dominated by dislocation slipping; when $\tau_{a}>1$, the deformation is dominated by twinning, and the larger the $\tau_{a}$, the stronger the twinning ability.

Another criterion is the grain boundary twinning criterion deduced by Asaro and Suresh [44], denoted by $\tau$. The formula is as follows:

$$
\tau=\sqrt{(1+2 \beta) \frac{\gamma_{u s f}}{\gamma_{u t f}}}, \beta=1-\gamma_{i s f} / \gamma_{u s f}
$$

A larger $\tau$ indicates an obvious tendency to twinning. However, since crack tips or grain boundaries are assumed, criteria $\tau_{a}$ and $\tau$ cannot be used to reveal the inherent twinnabilities of perfect fcc metals. The inherent twinnabilities are obtained by the following formula [45]:

$$
P=\frac{6}{\pi} \arctan \left[\frac{2\left(\gamma_{u s f}-\gamma_{i s f}\right)}{\sqrt{3}\left(\gamma_{u t f}-\gamma_{i s f}\right)}-\frac{1}{\sqrt{3}}\right]
$$

A larger $P$ value will promote the appearances of twins. All in all, these criteria show a similar situation. It can also be seen from Figure $11 b$, c that the values of $\delta_{\mathrm{us}}^{u t}$ and $\gamma_{u t f} / \gamma_{u s f}$ decrease when alloying elements are far from the stacking fault region. The values of $\tau_{a}, \tau$ and $P$ increase when Co and $\mathrm{W}$ are far from the stacking fault region, as shown in Figure 11d-f. It indicates that all systems are more likely to twinning when alloying elements $\mathrm{Co}$ and $\mathrm{W}$ are far from the stacking fault region. When $\mathrm{W}$ locates in the stacking fault region, the $\mathrm{Fe}_{35} \mathrm{Cr}_{18} \mathrm{Ni}_{18} \mathrm{~W}$ and the $\mathrm{Fe}_{34} \mathrm{Cr}_{18} \mathrm{Ni}_{18} \mathrm{~W}_{2}$ systems may be more susceptible to twinning. Conversely, when Co locates in the stacking fault region, the $\mathrm{Fe}_{35} \mathrm{Cr}_{18} \mathrm{Ni}_{18} \mathrm{Co}$ system and the $\mathrm{Fe}_{34} \mathrm{Cr}_{18} \mathrm{Ni}_{18} \mathrm{Co}_{2}$ system have little tendency to twinning. Furthermore, the tendency of the $\mathrm{Fe}_{34} \mathrm{Cr}_{18} \mathrm{Ni}_{18} \mathrm{CoW}$ system to deform is similar to the $\mathrm{Fe}_{35} \mathrm{Cr}_{18} \mathrm{Ni}_{18} \mathrm{Co}$ system when $\mathrm{Co}$ and $\mathrm{W}$ locate in the stacking fault region. It is noted that the calculated twinning abilities depends on the GSFE values, and the GSFE are directly linked with the distribution among the atoms. In conclusion, when Co and 
$\mathrm{W}$ are far from the stacking fault region, the GSFE values indicate that alloying with Co and $\mathrm{W}$ atoms are expected to bring a significant increase in the tendency for formation of partial dislocations and mechanical twinning. Plastic deformation by twinning will increase the amount of plastic deformation and promote grain refinement, so that the plasticity of the material can be increased [46]. Therefore, W can improve the plasticity of the system, which is consistent with the conclusions drawn in Figure 7.

\subsection{Experimental Results}

In order to verify the accuracy of the calculation results, we conducted a room temperature tensile test on Sanicro 25 steel with different $\mathrm{W}$ contents (1.5 wt.\% and $2.5 \mathrm{wt} . \%)$. The chemical composition of these two steels is shown in Table 3. The mechanical tensile tests performed were according to the GB/T228.1-2010 standard. The size of test samples is shown in Figure 12. The dog-bone shaped specimens with a gauge length of $23 \mathrm{~mm}$, thickness of $2 \mathrm{~mm}$ and width of $6 \mathrm{~mm}$ were cut from the Sanicro 25 steels after solution-treated at $1220^{\circ} \mathrm{C}$ for $1 \mathrm{~h}$ using a wire-cut electrical discharge machine (DK7720, Huadong Automation Co., Ltd., Taizhou, China), and then the surface was polished to a mirror-like finish. The tensile tests were carried out on an Instron 5582 testing machine (Instron, Boston, MA, USA) at a strain rate of $2 \times 10^{-4} \mathrm{~s}^{-1}$. Moreover, three identical specimens were measured to ensure accurate experimental data were obtained. Figure 13 shows the result of tensile testing at room temperature of two different $\mathrm{W}$ content Sanicro 25 steels. It can be seen from the stress-strain curve that increasing the $\mathrm{W}$ content increases its tensile strength, yield strength and plasticity. The calculation results of bulk modulus show that $\mathrm{W}$ will increase the compressive strength of the system, and the calculation results of Poisson's ratio and generalized stacking fault energy show that $\mathrm{W}$ will increase the plastic deformation ability of the system, which is consistent with the experimental stress-strain curve results and our previous work [47]. Although the calculation model systems are highly anisotropic, while the experimental samples after solution treatment are isotropic, the results of solid solution strengthening effects of $\mathrm{Co}$ and $\mathrm{W}$ in Sanicro 25 steel neglecting isotropic effects were of better credibility.

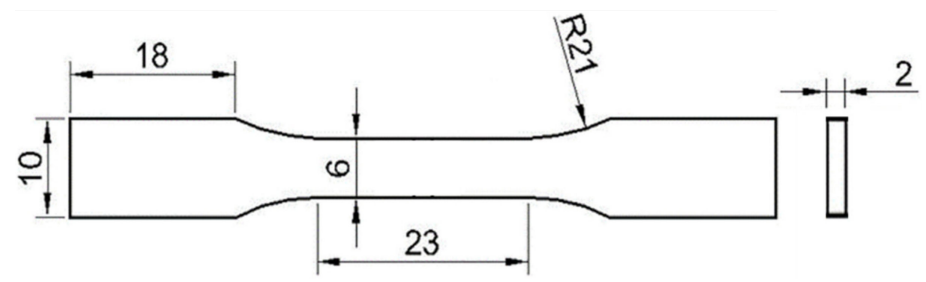

Figure 12. Schematic diagram of specimens for room-temperature tensile test (units: $\mathrm{mm}$ ).

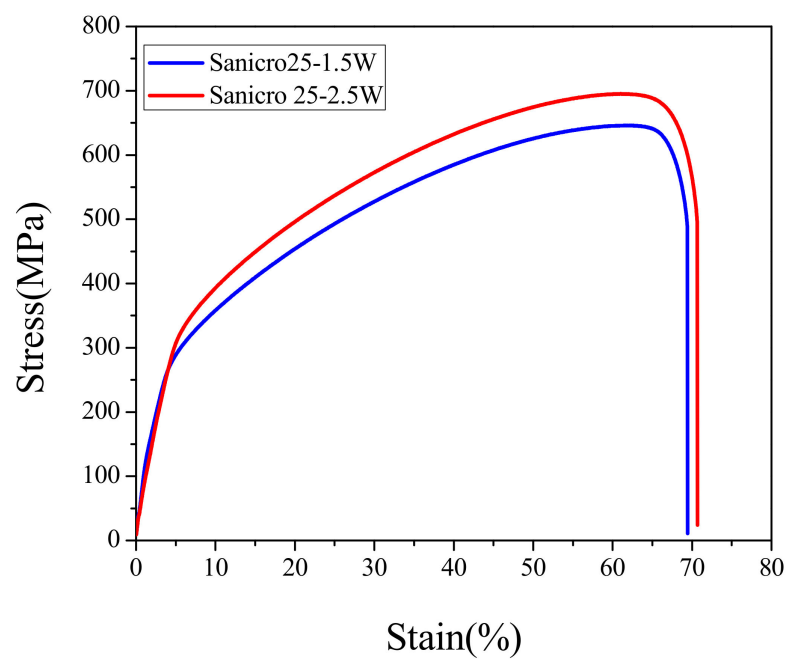

Figure 13. Stress-strain curves for two steels for room-temperature tensile. 
Table 3. Chemical compositions in weight \% (wt.\%) of two Sanicro 25 steels.

\begin{tabular}{cccccccccccccc}
\hline Steels & $\mathbf{C r}$ & $\mathbf{N i}$ & $\mathbf{C}$ & $\mathbf{S i}$ & $\mathbf{M n}$ & $\mathbf{W}$ & $\mathbf{C o}$ & $\mathbf{C u}$ & $\mathbf{N b}$ & $\mathbf{P}$ & $\mathbf{S}$ & $\mathbf{N}$ & $\mathbf{F e}$ \\
\hline Sanicro 25-1.5W & 21.66 & 24.54 & 0.065 & 0.27 & 0.74 & 2.31 & 4.62 & 2.84 & 0.45 & 0.01 & 0.003 & 0.14 & Bal. \\
Sanicro 25-2.5W & 21.47 & 24.36 & 0.060 & 0.25 & 0.76 & 1.42 & 4.62 & 2.74 & 0.44 & 0.01 & 0.002 & 0.13 & Bal. \\
\hline
\end{tabular}

\section{Conclusions}

In this work, we have revealed the effects of $\mathrm{Co}$ and $\mathrm{W}$ on structural stability and mechanical properties of Sanicro 25 austenitic heat-resistant steel through first principles calculations. The results of the present study are summarized as follows:

Based on the forming energy, the binding energy, charge density distribution maps and the Gibbs free energy, it can be concluded that Co and W can improve the structural stability and thermodynamic stability of Sanicro 25, that is, Co and W are stably present in Sanicro 25 steel. It is obvious that $\mathrm{W}$ has a great influence on the structural stability and thermodynamic stability of Sanicro 25 steel. We also calculate the elastic modulus, $B / G$ and Poisson's ratio, and we find that $W$ and a small amount of Co can improve the plasticity and ductility of Sanicro 25 steel. Furthermore, Peierls stress and evaluation of the GSFE values based on $\gamma_{u s f} / \gamma_{i s f}, \delta_{\mathrm{us}}^{u t}, \gamma_{u t f} f \gamma_{u s f}, \tau_{a}, \tau$ and $P$, concludes that the dominant deformation mechanisms of Sanicro 25 are extended partial dislocations and twinning. Moreover, the position of $\mathrm{Co}$ in the system has a great influence on the formation of partial dislocations and twinning. These results imply that alloying with $\mathrm{Co}$ and $\mathrm{W}$ atoms are expected to bring a significant increase in the tendency for formation of partial dislocations and twinning when Co and $\mathrm{W}$ are far from the stacking fault region. At two positions, $\mathrm{W}$ can significantly increase the possibility that the Fe-Cr-Ni system is deformed by twinning, thereby improving its plastic deformation ability. In short, W can significantly improve the structural stability and mechanical properties of Sanicro 25 compared to Co. Finally, combining experiment and calculation results, it is found that $\mathrm{W}$ can improve the strength and plasticity of the system.

Author Contributions: Conceptualization, N.D.; methodology, N.D., R.J. and X.F.; software, N.D., R.J. and J.Y.; data curation, R.J. and J.Y.; writing — original draft preparation, N.D. and R.J.; writing-review and editing, J.L. and P.H.; supervision, J.W. and P.H.; funding acquisition, N.D. and P.H. All authors have read and agreed to the published version of the manuscript.

Funding: This research was funded by the Natural Science Foundation of Shanxi Province (201801D221125), the National Natural Science Foundation of China (51871159 and U1860204), and Shanxi Engineering Technology Research Center for Energy Materials and Analysis and Testing.

Conflicts of Interest: The authors declare no conflict of interest.

\section{References}

1. Viswanathan, R.; Coleman, K.; Rao, U. Materials for ultra-supercritical coal-fired power plant boilers. Int. J. Press. Vessel. Pip. 2006, 83, 778-783. [CrossRef]

2. Dong, N.; Jia, R.; Wang, J.; Fan, G.; Fang, X.; Han, P. Composition optimum design and strengthening and toughening mechanisms of new alumina-forming austenitic heat-resistant steels. Metals 2019, 9, 921. [CrossRef]

3. Kloc, L.; Sklenička, V.; Dymáček, P. Transient effects in creep of sanicro 25 austenitic steel and their modelling. Metals 2019, 9, 245. [CrossRef]

4. Zurek, J.; Yang, S.M.; Lin, D.Y.; Hüttel, T.; Singheiser, L.; Quadakkers, W.J. Microstructural stability and oxidation behavior of Sanicro 25 during long-term steam exposure in the temperature range $600-750{ }^{\circ} \mathrm{C}$. Mater. Corros. 2015, 66, 315-327. [CrossRef]

5. Wang, B.; Liu, Z.-D.; Cheng, S.-C.; Liu, C.-M.; Wang, J.-Z. Microstructure evolution and mechanical properties of hr3c steel during long-term aging at high temperature. J. Iron Steel Res. Int. 2014, 21, 765-773. [CrossRef]

6. Dymáček, P.; Jary, M.; Dobeš, F.; Kloc, L. Tensile and creep testing of sanicro 25 using miniature specimens. Materials 2018, 11, 142. [CrossRef] [PubMed] 
7. Calmunger, M.; Chai, G.; Johansson, S.; Moverare, J. Creep and fatigue interaction behavior in sanicro 25 heat resistant austenitic stainless steel. Trans. Indian Inst. Met. 2016, 69, 337-342. [CrossRef]

8. Rutkowski, B.; Gil, A.; Czyrska-Filemonowicz, A. Microstructure and chemical composition of the oxide scale formed on the sanicro 25 steel tubes after fireside corrosion. Corros. Sci. 2016, 102, 373-383. [CrossRef]

9. Zhao, B.; Bao, H.S.; Li, L. Hot deformation behavior of Sanicro25 steel. Hot Work. Technol. 2014, 43, $26-30$.

10. Jang, M.-H.; Kang, J.-Y.; Jang, J.; Lee, T.-H.; Lee, C. Improved creep strength of alumina-forming austenitic heat-resistant steels through W addition. Mater. Sci. Eng. A 2017, 696, 70-79. [CrossRef]

11. Jang, M.-H.; Moon, J.; Kang, J.-Y.; Ha, H.-Y.; Choi, B.G.; Lee, T.-H.; Lee, C. Effect of tungsten addition on high-temperature properties and microstructure of alumina-forming austenitic heat-resistant steels. Mater. Sci. Eng. A 2015, 647, 163-169. [CrossRef]

12. Zhu, C.Z.; Yuan, Y.; Zhang, P.; Yang, Z.; Zhou, Y.; Huang, J.Y.; Yin, H.F.; Dang, Y.Y.; Zhao, X.B.; Lu, J.T.; et al. A modified HR3C austenitic heat-resistant steel for ultra-supercritical power plants applications beyond $650{ }^{\circ}$ C. Met. Mater. Trans. A 2017, 49, 434-438. [CrossRef]

13. Heczko, M.; Polák, J.; Kruml, T. Microstructure and dislocation arrangements in Sanicro 25 steel fatigued at ambient and elevated temperatures. Mater. Sci. Eng. A 2017, 680, 168-181. [CrossRef]

14. Zhou, R.; Zhu, L.; Liu, Y.; Lu, Z.; Chen, L.; Ma, X. Microstructural evolution and the effect on hardness of Sanicro 25 welded joint base metal after creep at 973 K. J. Mater. Sci. 2017, 52, 6161-6172. [CrossRef]

15. Wu, X.; Qi, Y.; Zhu, Y. Partial-mediated slips in nanocrystalline Ni at high strain rate. Appl. Phys. Lett. 2007, 90, 221911. [CrossRef]

16. Kivy, M.B.; Zaeem, M.A. Generalized stacking fault energies, ductilities, and twinnabilities of CoCrFeNi-based face-centered cubic high entropy alloys. Scr. Mater. 2017, 139, 83-86. [CrossRef]

17. Zhao, B.; Bao, H.; Liu, Z.; Li, L. Thermodynamic calculation and analysis on precipitated phases in Sanicro 25 heat resistant steel. Mater. Rev. 2012, 26, 174-179.

18. Li, C.-X.; Dang, S.; Wang, L.-P.; Zhang, C.; Pei-De, H. First-principles study of the effects of selected interstitial atoms on the generalized stacking fault energies, strength, and ductility of Ni. Chin. Phys. B 2014, 23, 117102. [CrossRef]

19. Chen, L.; Peng, P.; Li, G.; Liu, J.; Han, S. First-principle calculation of point defective structures of B2-RuAl intermetallic compound. Rare Metal Mat. Eng. 2006, 35, 1065-1070.

20. Jiang, D.; Wu, M.; Liu, D.; Li, F.; Chai, M.; Liu, S. Structural stability, electronic structures, mechanical properties and debye temperature of transition metal impurities in Tungsten: A first-principles study. Metals 2019, 9, 967. [CrossRef]

21. Zhu, S.-H.; Qin, H.; Zeng, W.; Cai, Y.-M.; Jin, X.-Y.; Wang, Y.-H.; Liu, F.-S.; Tang, B.; Liu, Q.-J. A comparative study of the vibrational and thermodynamic properties of $\alpha$-RDX and $\gamma$-RDX under ambient conditions. J. Mol. Model. 2019, 25, 182. [CrossRef] [PubMed]

22. Zhao, X.-S.; Yuan, G.-H.; Yao, M.-Y.; Yue, Q.; Shen, J.-Y. First-principles calculations and thermodynamic modeling of the V-Zr system. CALPHAD Comput. Coupling Phase Diagr. Thermochem. 2012, 36, 163-168. [CrossRef]

23. Chen, Q.; Huang, Z.; Zhao, Z.; Hu, C. Thermal stabilities, elastic properties and electronic structures of B2-MgRE (RE = Sc, Y, La) by first-principles calculations. Comput. Mater. Sci. 2013, 67, 196-202. [CrossRef]

24. Reeh, S.; Music, D.; Ekholm, M.; Abrikosov, I.A.; Schneider, J.M. Elastic properties of fcc Fe-Mn-X (X $=\mathrm{Cr}$, $\mathrm{Co}, \mathrm{Ni}, \mathrm{Cu}$ ) alloys from first-principles calculations. Phys. Rev. B 2013, 87, 2775-2781. [CrossRef]

25. Zhang, P.; Ma, Z.; Wang, Y.; Zou, Y.; Lei, W.; Pan, Y.; Lu, C.-S. A first principles study of the mechanical properties of Li-Sn alloys. RSC Adv. 2015, 5, 36022-36029. [CrossRef]

26. Du, J.; Wen, B.; Melnik, R.; Kawazoe, Y. Phase stability, elastic and electronic properties of Cu-Zr binary system intermetallic compounds: A first-principles study. J. Alloy. Compd. 2014, 588, 96-102. [CrossRef]

27. Zhan, Y.; Pang, M.; Wang, H.; Du, Y. The structural, electronic, elastic and optical properties of $\mathrm{AlCu}(\mathrm{Se} 1-x \mathrm{Tex}) 2$ compounds from first-principle calculations. Curr. Appl. Phys. 2012, 12, 373-379. [CrossRef]

28. Dou, Y.; Luo, H.; Zhang, J. Elastic Properties of FeCr20Ni8Xn (X= Mo, Nb, Ta, Ti, V, W and Zr) Austenitic Stainless Steels: A First Principles Study. Metals 2019, 9, 145. [CrossRef]

29. Dash, D.; Pandey, C.K.; Chaudhury, S.; Tripathy, S.K. Structure, stability and electronic properties of thin tio2 nanowires of different novel shapes: An Ab Initio study. Sci. Iran. 2019, 26, 1951-1961. [CrossRef] 
30. Pugh, S.F. Relations between the elastic moduli and the plastic properties of polycrystalline pure metals. Philos. Mag. 1954, 45, 823-843. [CrossRef]

31. Benyelloul, K.; Aourag, H. Elastic constants of austenitic stainless steel: Investigation by the first-principles calculations and the artificial neural network approach. Comput. Mater. Sci. 2013, 67, 353-358. [CrossRef]

32. Olivia, P.; Wilfredo, I.H.; Irais, V.J.; Sobhit, S.; Guillermo, A.F.; Dierk, R.; Aldo, H.R. Design of Mg alloys: The effects of $\mathrm{Li}$ concentration on the structure and elastic properties in the Mg-Li binary system by first principles calculations. J. Alloy. Compd. 2017, 691, 15-25.

33. Zhu, Y.; Yan, M.; Zhang, Y.; Zhang, C. First-principles investigation of structural, mechanical and electronic properties for $\mathrm{Cu}-\mathrm{Ti}$ intermetallics. Comput. Mater. Sci. 2016, 123, 70-78. [CrossRef]

34. Lv, L.; Chen, J.; Wang, P. First-principles calculations for the microscopic properties of Ir, Cu, Si and Au. Precious Met. 2013, 34, 61-67.

35. Tian, L.-Y.; Lizárraga, R.; Larsson, H.; Holmstrom, E.; Vitos, L. A first principles study of the stacking fault energies for fcc Co-based binary alloys. Acta Mater. 2017, 136, 215-223. [CrossRef]

36. Walter, M.; Roncery, L.M.; Weber, S.; Leich, L.; Theisen, W. XRD measurement of stacking fault energy of Cr-Ni austenitic steels: Influence of temperature and alloying elements. J. Mater. Sci. 2020, 55, 13424-13437. [CrossRef]

37. Latanision, R.M.; Ruff, A.W. The temperature dependence of stacking fault energy in Fe-Cr-Ni alloys. Met. Mater. Trans. A 1971, 2, 505-509. [CrossRef]

38. Liu, J.; Han, P.; Dong, M.; Fan, G.; Qiao, G.; Yang, J. Influence of Ni and N on generalized stacking-fault energies in Fe-Cr-Ni alloy: A first principle study. Phys. B Condens. Matter 2012, 407, 891-895. [CrossRef]

39. Achmad, T.L.; Fu, W.; Chen, H.; Zhang, C.; Yang, Z.-G. First-principles calculations of generalized-stacking-fault-energy of Co-based alloys. Comput. Mater. Sci. 2016, 121, 86-96. [CrossRef]

40. Van Swygenhoven, H.; Derlet, P.M.; Frøseth, A.G. Stacking fault energies and slip in nanocrystalline metals. Nat. Mater. 2004, 3, 399-403. [CrossRef]

41. Tadmor, E.; Hai, S. A Peierls criterion for the onset of deformation twinning at a crack tip. J. Mech. Phys. Solids 2003, 51, 765-793. [CrossRef]

42. Tadmor, E. A first-principles measure for the twinnability of FCC metals. J. Mech. Phys. Solids 2004, 52, 2507-2519. [CrossRef]

43. Bernstein, N.; Tadmor, E. Tight-binding calculations of stacking energies and twinnability in fcc metals. Phys. Rev. B 2004, 69, 50-55. [CrossRef]

44. Asaro, R.J.; Suresh, S. Mechanistic models for the activation volume and rate sensitivity in metals with nanocrystalline grains and nano-scale twins. Acta Mater. 2005, 53, 3369-3382. [CrossRef]

45. Li, B.; Sui, M.; Mao, S.X. Twinnability predication for fcc metals. J. Mater. Sci. Technol. 2011, 27, 97-100. [CrossRef]

46. Molnar, D.; Sun, X.; Lu, S.; Li, W.; Engberg, G.; Vitos, L. Effect of temperature on the stacking fault energy and deformation behaviour in 316L austenitic stainless steel. Mater. Sci. Eng. A 2019, 759, 490-497. [CrossRef]

47. Wang, L.; Fang, X.D.; Wang, J.; Zhang, Z.X. The precipitation control of grain boundary M23C6 phases and the ductility improvement in aged austenitic stainless steel $22 \mathrm{Cr}-25 \mathrm{Ni}-\mathrm{WCuNbN}$ by Co addition. Mat. Let. 2020, 264, 127348. [CrossRef]

(C) 2020 by the authors. Licensee MDPI, Basel, Switzerland. This article is an open access article distributed under the terms and conditions of the Creative Commons Attribution (CC BY) license (http://creativecommons.org/licenses/by/4.0/). 